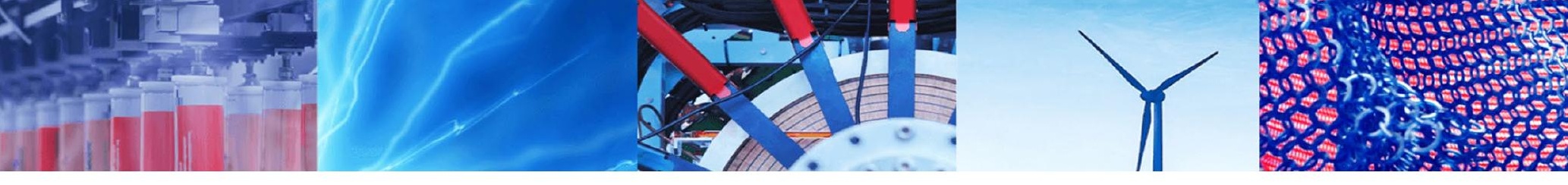

Research Article

\title{
Laser polished fused deposition poly-lactic acid objects for personalized orthopaedic application
}

\author{
Yuan Chai ${ }^{1} \cdot$ Xiao-Bo Chen ${ }^{2}$. Donghai Zhang ${ }^{1} \cdot$ Joseph Lynch $^{1} \cdot$ Nick Birbilis $^{3} \cdot$ Qing-Hua Qin $^{3} \cdot$ Paul N. Smith ${ }^{4}$. \\ Rachel W. Li ${ }^{1,5}$
}

Received: 26 June 2020 / Accepted: 7 October 2020 / Published online: 17 October 2020

(c) The Author(s) $2020 \quad$ OPEN

\begin{abstract}
Patient-specific surgical guides are increasingly demanded. Material Extrusion (ME) is a popular 3D printing technique to fabricate personalized surgical guides. However, the ME process usually generates deleterious surface topography which is not suitable for orthopaedic emergencies. We designed and optimized parametric combinations of a laser polishing approach as post process to improve the surface quality of ME-made poly-lactic acid (PLA) objects. In this study, we investigated the contribution of processing variables to the mechanical properties and the biocompatibilities in vitro of the ME-made PLA objects. Conventional surface grinding was conducted as comparison. The results demonstrate that the ME-made PLA samples exhibit good mechanical properties and favourable biocompatibility after being post processed using laser polishing. The post laser polishing, as a powerful tool in manufacture of ME-made PLA objects, will open a new approach with a great promise in its applications in personalized and timely management of medical emergencies.
\end{abstract}

Keywords Biocompatibility · Fused deposition modelling · Mechanical strength · Orthopaedics · Surgical guide · Three dimensional printing

\section{Introduction}

Orthopaedic implants and surgical guides are usually standardized products that are categorized into a limited number of sizes to fit all patients [1]. However, bone geometrical and structural parameters and the complexity of a traumatic injury or joint reconstruction vary individually $[2,3]$. Consequently, the geometric mismatch between a surgical device and individual bone increases the possibility of nerve roots or visceral damage $[4,5]$, biomechanical disadvantages [6], implant mobility and loosening [7], and implant failure [8]. Good fitting accuracy of implants or surgical guides will reduce the risk of body rejection and complications, and influence on the osseointegration at the interface between bone and implants after surgery, which will largely improve clinical outcomes. Therefore, customized patient-specific medical implants with an accurate implant configuration and appropriate implant placement have become attractive [9]. Likewise, patientspecific surgical guides are increasingly demanded, particularly by orthopaedic surgeons worldwide in planning their surgeries and improving the accuracy during their performances [10].

Three-dimensional (3D) printing, a modern additive manufacturing technology, emerges as asimple and feasible solution to the manufacturing issue related to

$\triangle$ Rachel W. Li, rachel.li@anu.edu.au| ${ }^{1}$ Trauma and Orthopaedic Research Laboratory, Department of Surgery, The Medical School, The Australian National University, Canberra, ACT 2601, Australia. ${ }^{2}$ School of Engineering, RMIT University, Carlton, VIC 3053, Australia. ${ }^{3}$ Research School of Engineering, College of Engineering and Computer Science, Australian National University, Canberra, ACT 2601, Australia. ${ }^{4}$ Trauma and Orthopaedic Research Unit, The Canberra Hospital, Yamba Drive, Garran, ACT 2605, Australia. ${ }^{5}$ Department of Immunology and Infectious Disease, John Curtin School of Medical Research, The Australian National University, Acton, ACT 0200, Australia. 
medical devices that are highly demanded by medical field, particularly in orthopaedic emergencies because it buildspatient-specific models and fabricate surgical guides and implants. To date, material extrusion (ME) is the most commonly used and the most accessible 3D printing technology for customized medical applications [11]. A hotend tip extrudes melted material filament which solidifies at the designated spatial position of a proposed 3D model. This technique allows physical fabrication from a computer-aid-design (CAD) model at a relatively low cost [12].

Poly-lactic acid (PLA) is one of the most commonly used thermoplastic materials in ME printing which has been shown to have sufficient geometrical accuracy [13], strength resistance and good biocompatibility in vitro [14, 15]. ME prototypes have been used successfully as guiding instruments to assist surgical procedures [16-18]. However, a number of limitations still exist. Research showed that the ME process changes the chemical properties of the original PLA, making it more susceptible to degradation in physiological conditions [19]. Such PLA objects exhibit a rough surface topography, specifically a staircase surface texture with a low directional resolution [20, 21]. Surface roughness of a bio-material is essential to its mechanical strength and cell growth [22]. Poor surface quality of the ME-made PLA parts that contains the deleterious staircase structure constrains their application as a final product for medical applications. Other than improving the surface quality by optimizing the processing parameters [23,24], post surface treatment reduces the deleterious staircase surface characteristics of ME products, which can be directly quantified by a reduction of surface roughness. Studies have investigated different post processing methods for improving surface quality of the ME products $[25,26]$, such as barrel finishing, vapour smoothing and chemical etching techniques $[27,28]$. These methods are currently offering available options for post surface processing on the ME-made PLA parts. However, the disadvantages, such as chemical contamination, high production cost and long processing time length make them impractical to the use in emergent medical situations, like trauma management.

Laser scanning for post polishing of metal 3D printing prototypes has been widely used [29, 30]. Although the laser treatment usually applies on polishing of flat surface because of its technical nature, the laser polishing is greatly desired for medical device manufacturing because it possesses contactless and wearless machining abilities and penetrates material surface to polish the inner structure [31-33]. Our laboratory and other researchers developed a novel laser polishing method on polymer 3D printed object, and conducted preliminary studies [34, 35]. Although researchers have reported the mechanical strength of PLA composite with or without laser polishing, the mechanical and biocompatible behaviours of laser post processed ME-made PLA object have not been fully investigated [36, 37]. Its feasibility on orthopaedic application remains unknown. In this study, we explored the contribution of processing variables to the mechanical properties and biocompatibilities of ME-made PLA and identified the optimal set of laser scanning parameters. Conventional mechanical grinding was conducted as comparison. We expect to provide comprehensive experimental evidence to support the post laser polishing as a powerful tool in manufacture of ME-made PLA objects for the use in personalized and timely management of medical emergencies.

\section{Material and methods}

\subsection{D printing}

As demonstrated in Fig. 1, the 3D model contains three different parts to fill in a solid material. The first part is a brim, i.e. fringe of a model at each layer, where the extruder scans. The second part is infill, in which the inside area of the model is filled by a proposed pattern and density. The third part is a supporting structure which refers to the features that do not exist in the 3D model, but support the upper layer to maintain its spatial position. The 3D model was designed using Solidworks (Dassault Systemes SA, France), and were converted to.stl file to be recognizable by the 3D printer. The slicing strategy was generated using the software Simplify3D (Simplify3D, OH, USA). To examine the mechanical properties of the ME-made PLA objects and post processed with the laser scanning, we designed

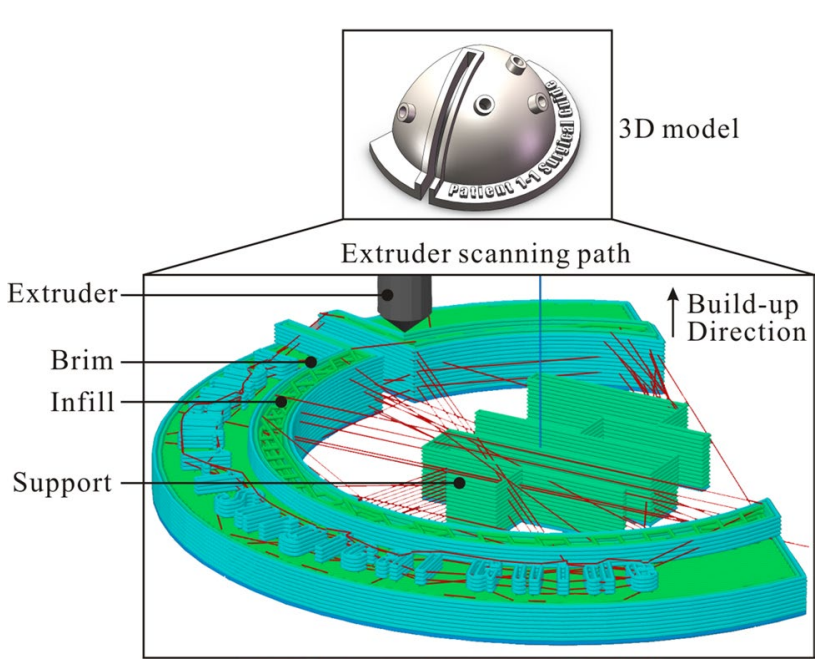

Fig. 1 Schematic diagram of 3D printing 
model geometries based on the requirements of International Organization for Standardization (ISO). We prepared samples for tensile and compression tests and flexural properties under the defined conditions according to the standards of ISO 527 [38], ISO 604 [39], and ISO 178 [40], respectively. In addition to the mechanical tests, we also prepared sample discs for in vitro biocompatibility test at $12 \mathrm{~mm}$ radius and $1.5 \mathrm{~mm}$ thickness, with a surface area of $1.02 \mathrm{~cm}^{2}$. These parameters were determined according to ISO 10,993-5 [41], including the requirement of a ratio between the size of test sample and density of cell seeding. This study focuses on the mechanical and biocompatible comparison of post treated samples, thus the influence of complex sample geometry is not discussed.

We used an aluminium frame reinforced self-assembly deltabot ME 3D printer to manufacture PLA components for surface polishing experiments. We selected white PLA filaments with a $1.75 \mathrm{~mm}$ (Sunhokey-tec, Guangdong, China) as stock materials owing to their good thermal performance and environmentally friendly nature. During ME process, samples for mechanical testing were oriented flatly and for interlayer bonding were oriented vertically. Parameters were set as $195{ }^{\circ} \mathrm{C}$ extrusion temperature and $60{ }^{\circ} \mathrm{C}$ bed temperature, $60 \mathrm{~mm} / \mathrm{s}$ printing speed, $70 \%$ infill density and rectilinear infill pattern with double brim. In contrast, samples for biocompatibility testing were printed vertically and made in $100 \%$ solid infill to avoid hollow interior. All models were sliced at $0.25 \mathrm{~mm}$ layer thickness.

\subsection{Post processing using laser scanning}

We used a 40 W laser scanning machine (King Rabbit HX40A, Shandong, P.R. of China) and a mechanical grinding machine to prepare the test samples. To achieve shallow melt regime on the surface, we used a set of the parameters of laser polishing treatment at $3 \mathrm{~W}$ output power, $0.025 \mathrm{~mm}$ scan line gap, $30 \mathrm{~ms}$ delay between pulses, and $150 \mathrm{~mm} / \mathrm{s}$ scan speed as previously described [35]. A square area that fully covered the sample was scanned by laser and each laser pulse scanned along the short side. Samples were post processed at all sides of faces. A 700 grit sandpaper was applied with water as lubricant at a rotation speed of $150 \mathrm{r} / \mathrm{min}$ for mechanical surface grinding. Although the manually controlled grinding pressure could hardly be quantified to a standard procedure, we optimised and set the grinding duration at 40-50 s/corresponding side. A grinding depth of $0.25 \mathrm{~mm}$ was achieved at each side.

\subsection{Validation of surface roughness}

A Wyko NT1100 optical profiler (Veeco, AZ, USA) was used to determine the surface roughness $\left(S_{a}\right)(\mu \mathrm{m})$ of the
ME-made PLA samples before and after post surface treatment [42], shown below:

$S_{a}[\mu m]=\frac{1}{A} \iint_{A}\left|Z_{(x, y)}\right| d x d y$

The effectiveness of the topography optimization was evaluated by the roughness reduction of surface (\%), shown below:

$S_{a_{\text {reduction }}}[\%]=\frac{S_{a_{\text {initial }}}-S_{a_{\text {polished }}}}{S_{a_{\text {initial }}}} \times 100$

An area of $1.3 \times 0.9 \mathrm{~mm} 2$ that contained over 5 layers of waviness on each sample was scanned to calculate the overall surface roughness. The same area of scan was applied on measuring the grinded samples that had no obvious waviness.

\subsection{Mechanical properties}

An Instron mechanical tester (Instron ${ }^{\oplus} 4505$, MA, USA) was employed for investigating tensile, compression and flexure properties of the PLA parts at room temperature, $23^{\circ} \mathrm{C}$ and $50 \%$ relative humidity according to the standards of ISO 527. To quantify mass loss during the laser polishing treatment, the samples were weighted before and after the post processing on an electronic balance with an accuracy of $0.0001 \mathrm{~g}$. In tensile test, velocity was $5 \mathrm{~mm} / \mathrm{min}$ and the specimen was loaded until it was broken with a load cell of $5 \mathrm{kN}$. In compression test, cross-sectional dimensions after post processing were measured using a $50 \mathrm{kN}$ load cell and velocity at $1.3 \mathrm{~mm} / \mathrm{min}$. We used the same load cell for flexural test at a speed of $2 \mathrm{~mm} / \mathrm{min}$. The three point bending method was used, with a load cell of $5 \mathrm{kN}$ and a speed of $2 \mathrm{~mm} / \mathrm{min}$, to calculate the flexural modulus.

\subsection{Biocompatibility testing}

We further investigated cytotoxicity of the various MEmade PLA samples in vitro by culturing bone cells on their surface [41]. Three groups of PLA disks were used in this study, i.e. laser scanning polished, as-printed and mechanical grinded discs (control groups). Sample discs were immersed in deionized water for ultrasonic cleaning for $20 \mathrm{~min}$, and irradiated with UV light for $30 \mathrm{~min}$ on each side for further use.

Human primary osteoblast cells (OBs), human osteoclast cells (OCs) and human Saos-2 cell line supplied by ECACC (Sigma, Melbourne, Australia) were used in in vitro cytotoxicity test. The human primary OBs were derived from normal human trabecular bone specimens as we previously 
described with mild modifications [8], with the permission of the Australia Capital Territory (ACT) Health Human Research Ethics Committee (Ref. ETH.9.07.865). To assess whether the different material discs influence on $\mathrm{OB}$ cell growth, the cells were seeded at a density of $5 \times 10^{3}$ cells per well in $1 \mathrm{~mL}$ of cell culture medium in 24-well plate containing discs. The cells were cultured at $37^{\circ} \mathrm{C}, 5 \% \mathrm{CO}_{2}$ for 3 days before were measured for cell density. The experiments were performed at triplicates in each sample group. At the end point, the cells were washed, trypsinized, and resuspended in cold PBS. The cells were counted using Vi-CELL ${ }^{\text {TM }}$ Cell Viability Analyser (Beckman Coulter, IN, USA). Cell numbers represented the quantity of surviving cells on each disc.

The human OCs were induced from "buffy coat" (a 42-year-old male volunteer) provided by Australian Red Cross Blood Service with approval from Human Research Ethics Committee of Australian National University (Ref. 2014/253). Peripheral blood mononuclear cells (PBMCs) were separated from the buffy coat as we descripted previously [43], and approximately $2.5 \times 105$ cells were placed in a well of 12-well plate containing the sample disc in $1 \mathrm{~mL}$ of $\mathrm{OC}$ conditional culture medium. The medium is a a-MEM based with supplements of $10 \%$ FCS and antibiotics, $10 \times 10-9$ M dexamethasone Sigma-Aldrich, Australia), $25 \mathrm{ng} \mathrm{mL}-1$ human M-CSF (Merck Millipore, Australia), and 10×10-9 M 1,25(OH)2D3 (Sigma-Aldrich, Australia). Cell culture medium was refreshed every 2 days. The OC inductive medium supplemented with recombinant human RANKL (Merck Millipore) at $50 \mathrm{ng} \mathrm{mL}-1$ was used and the induced OCs were measure at the day 8 of culture. In the Vi-CELL ${ }^{\text {TM }}$ Cell Viability Analyser, we set $70 \mu \mathrm{m}$ filter for cells selected as induced matured/prematured OCs. Three independent experiments were performed by two independent researchers.

\subsection{Statistical analysis}

Experimental data were analysed using software Graphpad Prism7.0 (GraphPad Software, Inc. CA, USA). Student t-test was performed to analyse differences between two means in the experiments. Data is Gaussian distribution without equal standard deviations (SDs) for unpaired comparison. Welch's correction was applied. The statistical significance was set at $p \leq 0.05$. Three to six replicates of each experiment were performed.

\section{Results and discussion}

\subsection{Surface morphologies of post treatment}

Surface roughness of FDM-made PLA samples polished by laser scanning and grinding are shown in Table 1. The laser scanning reduced $47 \%$ surface roughness and the grinding $94 \%$. We noted that the surface roughness reduction was not as much as that on laser polishing metal material, laser treatment of polymer still has great potential when it attract more researchers. The profiles of cross-sectional surfaces are shown in Fig. 2. As-printed PLA surface and laser treated surface present a heterogeneous character. We noted that laser scanning evaporated a thin layer of surface material in Figs. 2a, b. We further measured the height difference of a single layer between as-printed area and laser scanned area in Fig. 2c, the later showed a surface roughness at $9.78 \mu \mathrm{m}$. We found that the laser evaporated area declined $24.18 \pm 4.28 \mu \mathrm{m}$ compared to that of as-printed ( $n=5$ per group). The result indicates that parameters of laser polishing treatment that we set for this project induced ignorable material evaporation.

In this study, only the flat surfaces were laser treated due technology and equipment limitation. Studies reported successful applying laser surface treatment onto curved or complex surface geometry. We planned further investigation about the influence of different sample geometries on laser polishing outcome $[44,45]$. It worth to note that a sample at high area-volume ratio may not be suitable to apply laser processing method to improve the surface quality, such as lattice structure. Although the geometry is rare in surgical guide design, an alternative surface treatment method might be required, such as vapour smoothing [28].

\subsection{Influence of laser polishing on tensile stress}

Slight weight reduction is a common phenomenon after post surface processing. In this study, we measured the weight of samples from all groups and found that both laser and grinding treatments reduced the weight of samples as showed in Table 2. Next, we compared the tensile properties of laser treated samples to that of as-printed and grinded samples as showed in Table 2. There was no significant difference in tensile strain and Young's modulus at break in the samples post processed either using laser polishing or grinding when compared with the as-printed samples. Even though the weight of samples was reduced

Table 1 Surface roughness of samples with different post treatments

\begin{tabular}{lcl}
\hline Surface type & Surface roughness $(\mu \mathrm{m})$ & $\begin{array}{l}\text { Roughness } \\
\text { reduction } \\
(\%)\end{array}$ \\
\hline As-printed & $14.42 \pm 2.55$ & \\
Laser treated & $7.68 \pm 0.65$ & 47 \\
Grinded & $0.88 \pm 0.18$ & 94 \\
\hline
\end{tabular}

Data represent mean of 3 replicates, \pm SD 
by laser treatment from 7.52 to $6.98 \mathrm{~g}(7.18 \%)$, the ultimate tensile stress (UTS) was not significantly influenced $(p>0.05)$.

Technical schematic diagrams are presented in Fig. 3a, which demonstrates samples geometry, post treated faces, and force direction. The stress-strain curves of the as-printed, laser treated, and grinded samples are shown in Fig. $3 \mathrm{~b}$ and experimental setup is presented in Fig. 3c.
The morphologies of interlayer breaks are shown in Fig. 3d. The laser treated samples had slightly higher UTS than that of the grinded samples at break as presented by red and blue curves, respectively, in Fig. 3b. Our results suggested that the tensile performance is, to some extent, related to the thickness of outer shell of sample. This is agreed with the results by Bagsik et al. who found that the tensile stress of samples build up in the side direction were higher

Fig. 2 Surface profile. a surface roughness, images taken from inverted microscope; $\mathbf{b}$ Quantitative measurement of surface waviness of 3D printed samples under different post treatment; c Surface profile of the peak of a layer

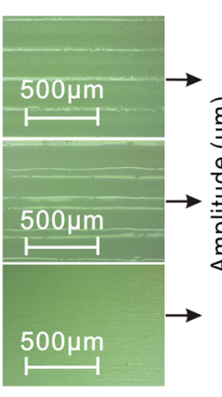

(a)

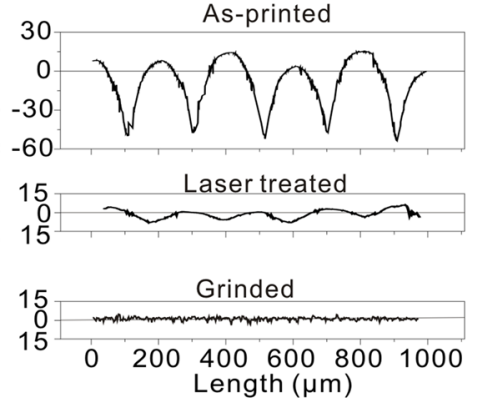

(b)

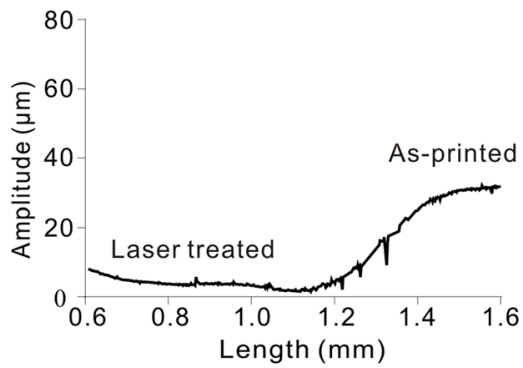

(c)

Table 2 Summary of weight and tensile test

\begin{tabular}{|c|c|c|c|c|c|c|c|c|c|c|}
\hline & Weight (g) & $\mathrm{p}$ & $\begin{array}{l}\text { UTS } \\
\text { (MPa) }\end{array}$ & $\mathrm{p}$ & Strain at UTS (\%) & $\mathrm{p}$ & $\begin{array}{l}\text { Young's } \\
\text { modulus } \\
(\mathrm{GPa})\end{array}$ & $\mathrm{p}$ & $\begin{array}{l}\text { Transverse young's } \\
\text { modulus }(\mathrm{GPa})\end{array}$ & $p$ \\
\hline As-printed & $7.52 \pm 0.04$ & & $28.47 \pm 1.30$ & & $2.53 \pm 0.46$ & & $1.15 \pm 0.23$ & & $0.76 \pm 0.12$ & \\
\hline Laser treated & $6.98 \pm 0.01$ & $<0.01$ & $26.36 \pm 2.24$ & 0.25 & $2.25 \pm 0.24$ & 0.41 & $1.18 \pm 0.11$ & 0.87 & $0.75 \pm 0.12$ & 1.00 \\
\hline Grinded & $6.23 \pm 0.12$ & $<0.01$ & $21.94 \pm 2.10$ & 0.02 & $2.21 \pm 0.16$ & 0.35 & $0.99 \pm 0.04$ & 0.35 & $0.99 \pm 0.06$ & 0.06 \\
\hline
\end{tabular}

UTS, ultimate tensile strength; Data represents mean \pm SD of triplicates; $p$ test groups compared to as-printed group

Fig. 3 Tensile test. a Schematic of tensile test; $\mathbf{b}$ Stress-strain curves of FDM specimens with different post processing. Grinded samples had lower ultimate tensile stress at all the three repeats; $\mathbf{c}$ The experimental setup of tensile; $\mathbf{d}$ SEM images of the morphologies of the edges at the break interlayer (a)

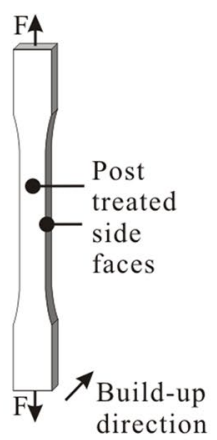

(d)

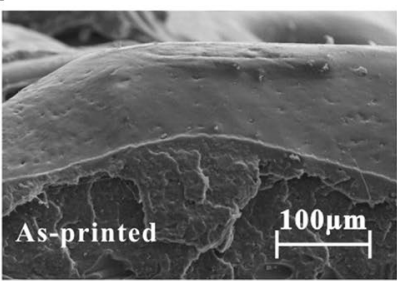

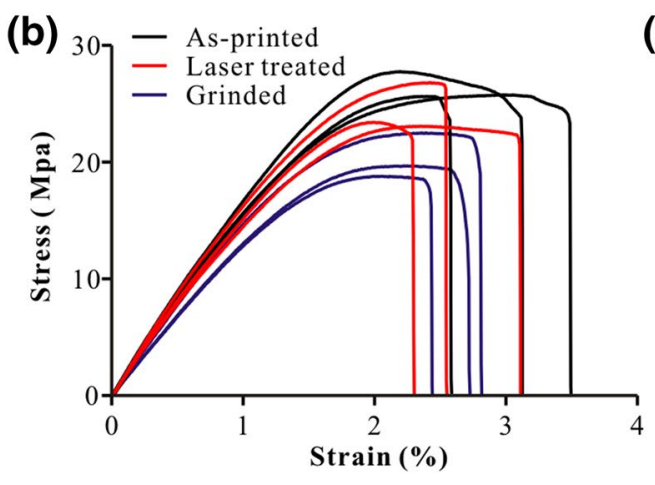

(c)

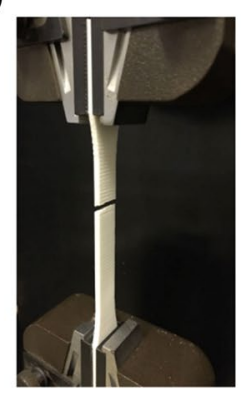

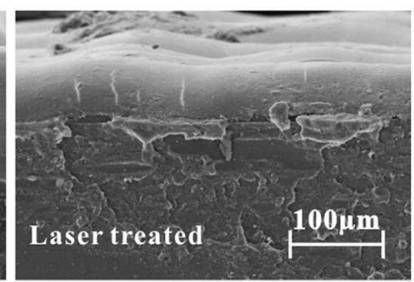

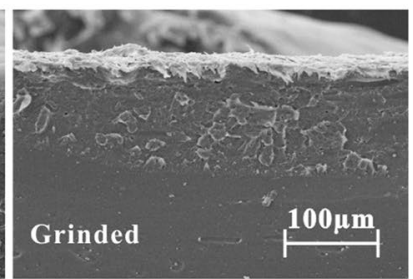


Fig. 4 Compression test. a Schematic of compression test; b stress-strain curves of FDM specimens with different post processing; c Different compressive break morphology of specimens before and after post treatment. More cracks were generated on rougher surface at layer bonding area. Cracks were evenly distributed between layers
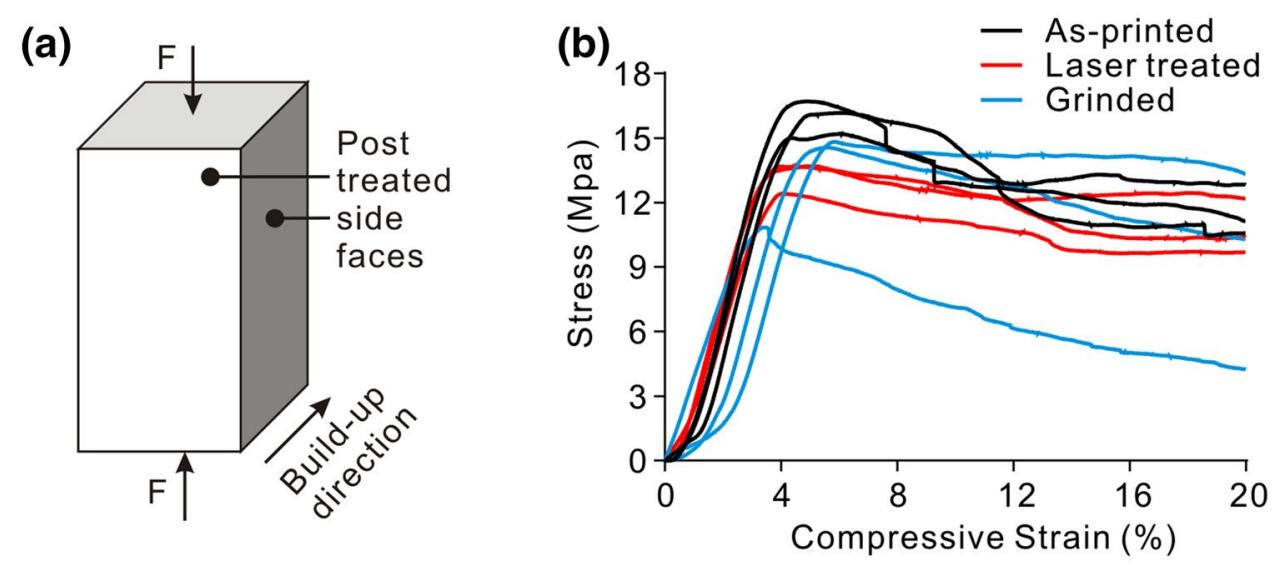

(c)

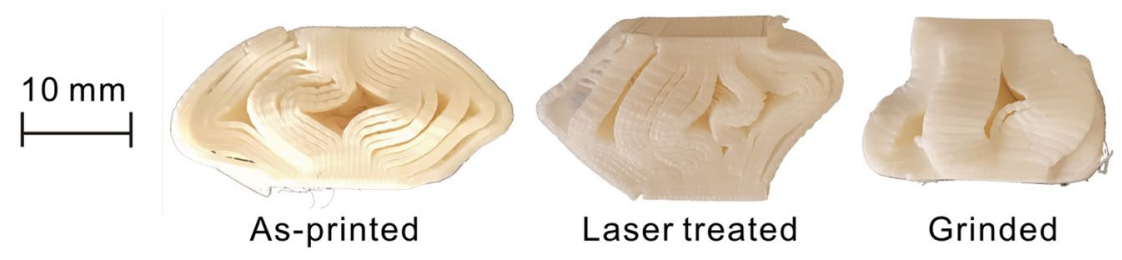

than the one build up in the flat direction [46]. The higher tensile stress may also be a result of more build-in shell material along the force direction. This is also ascribed to the low adhesion strength between layers. Further interlayer bonding experiments validated that a more uniformed surface makes the object less likely to break at the binding interface between layers, i.e. isotropic surface at low surface roughness. In Fig. $3 d$, the as-printed sample showed clear border where layers bonded and then broke along. The laser treated sample had flatter waviness, and the border was less clear, but the stress concentration was not reduced. As shown in Table 2, there was no difference between as-printed and laser treated samples $(p=1.00)$, and between as-printed and grinded samples $(p=0.06)$. The raster infill structure can be improved in the software algorithm to change the mechanical property to be suitable for a specific load bearing task [47]. It is worth to note that comparing to the strength of polypropylene which is also widely applied in medical device fabrication, laser treated ME-made PLA samples showed 19.82\% higher UTS than that of pure polypropylene samples [48]. This provides supporting evidence to the potential of the proposed surgical guide application.

\subsection{Laser polishing achieved favourable compressive stress}

To understand the mechanisms that laser treatment achieved a favourable compressive stress, we further investigated the factors, which could be related to compressive stress, such as weight, deformation morphologies of samples' surface, and infill density. Both post treatments generally reduced the ultimate compressive stress $(\sigma B)$ compared with that of as-printed samples as shown in Fig. 4b. As we can see from Table 3, the samples in asprinted group presented the maximum stress. The reduction of maximum $\sigma B$ might due to the weight loss during the post processing. The dimensional reduction by surface treatment reduced cross-sectional area. However, it was not sufficient to compensate the decline of compressive stress. This might be an explanation of the $\sigma B$ reduction. In addition, there was no statistically significance difference between groups on compressive strain when the samples were broken $(p>0.05)$, regardless of whether the samples were with or without post processing.

Interestingly, we also noted that the deformation morphologies of the samples are different as shown in Fig. 4c. In addition to the Young's Modulus of interlayers that the anisotropic surface is lower than the isotropic surface, this is a further evidence of weak adhesion between the layers when there was no solid infill density. Compressive behaviour in this study is also different from that of a solid material test reported by other researchers [46], in which a break caused by shear strain can be found. This is because our study reduced infill density from $100 \%$ solid to $70 \%$ to fabricate the samples, which consumed a shorter manufacturing time. 
Table 3 Summary of weight and compression test

\begin{tabular}{llrllll}
\hline & Weight (g) & $\mathrm{p}$ & $\begin{array}{l}\text { Ultimate compres- } \\
\text { sive stress (MPa) }\end{array}$ & $\mathrm{p}$ & $\begin{array}{l}\text { Compressive strain } \\
\text { at break (\%) }\end{array}$ & $\mathrm{p}$ \\
\hline As-printed & $3.21 \pm 0.03$ & & $16.02 \pm 0.73$ & & $5.72 \pm 0.74$ & \\
Laser treated & $2.99 \pm 0.01$ & $<0.01$ & $13.26 \pm 0.73$ & 0.01 & $4.35 \pm 0.59$ & 0.38 \\
Grinded & $2.96 \pm 0.08$ & 0.02 & $13.41 \pm 2.22$ & 0.17 & $4.95 \pm 1.28$ & 0.81 \\
\hline
\end{tabular}

Data represents mean $\pm S D$ of triplicates; $p$ test groups compared to as-printed group (a)

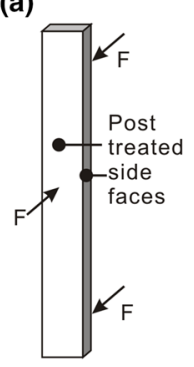

(b)

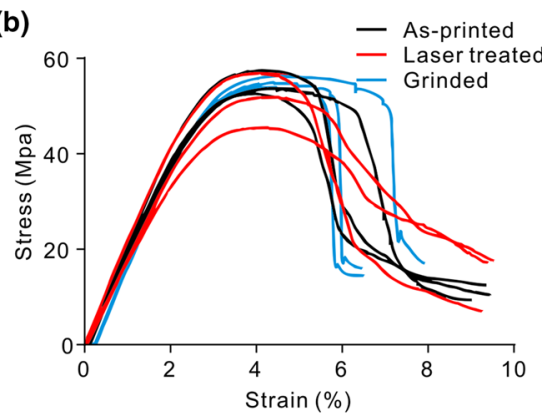

Fig. 5 Flexure test. a Schematic of flexure test; b Stress-strain curves of ME specimens with different post processing. There is no statistically significant difference, but grinded samples exhibited brittle fracture

\subsection{Influence of post treatment on flexure stress}

We further analysed differences in flexural modulus, flexural stress and flexure strain of ME-made PLA samples post treated using laser and grinding. The laser treated samples demonstrated similar results to the as-printed samples in the flexure test, while the grinded samples exhibited brittle fracture in Fig. 5b. As presented in Table 4, laser treated samples showed no difference in all parameters compared with those of as-printed samples at break $(p>0.05)$. The grinded samples reached brittle fracture as we reported in the last section, but the weight reduction in the samples grinded was in an acceptable range (5\%).

However, there is no significant increase on flexure strain at break when samples were post grinded, which was calculated from the deflection correspondent to the maximum load. As shown in Fig. 5b, we noted that the

stress-strain curves of grinded samples (blue curves) declined dramatically at a short deflection. We infer that the heterogeneity surface, surface at high roughness in this study, reduces the overall rigidity of PLA samples. Therefore, we can conclude that the smoother surface influenced on the flexural capacity of object.

\subsection{Laser polishing had less reduction of mechanical properties}

There is no statistical difference in Young's Modulus, flexural modulus, and flexure stress at break. Grinding reduced tensile stress and compressive stress with deformed samples, and laser treatment reduced compressive stress at break. We calculated the reduction of mechanical properties from Table 2, 3, 4. Among all mechanical tests of laser treated samples, a maximum of $17.24 \%$ stress reduction at break was found (compression from 16.02 to $13.26 \mathrm{MPa}$ ), with an average reduction of $9.40 \%$. Ultimate compression stress was sensitive to the post laser treatment that has statistical reduction $(p<0.05)$. Tensile strength and flexure property on average only reduced $7.41 \%$ from 28.47 to $26.36 \mathrm{MPa}$ and $3.56 \%$ from 56.89 to $54.87 \mathrm{MPa}$ after laser processing, respectively. In comparison, grinding reduced $16.30 \%$ ultimate compressive stress from 16.02 to $13.41 \mathrm{MPa}(p>0.05), 22.95 \%$ UTS (from 28.47 to $21.94 \mathrm{MPa}$ ), and $6.00 \%$ flexural stress at break from 56.89 to $53.48 \mathrm{MPa}$, which on average $5.68 \%$ lower than that of laser polished samples.

We infer that the post surface treatment made the object more likely to break under compression, and varying material weights might significantly influence the tensile property. However, the resistance to deformation was statistically no difference as shown in all strain analyses.
Table 4 Summary of weight and flexure test

\begin{tabular}{lcccccccc}
\hline & Weight (g) & $\mathrm{p}$ & $\begin{array}{l}\text { Flexure stress } \\
\text { at break (MPa) }\end{array}$ & $\mathrm{p}$ & $\begin{array}{l}\text { Flexure strain } \\
\text { at break (\%) }\end{array}$ & $\mathrm{p}$ & $\begin{array}{l}\text { Flexural } \\
\text { modulus }( \\
\mathrm{GPa})\end{array}$ & $\mathrm{p}$ \\
\hline As-printed & $2.70 \pm 0.05$ & & $56.89 \pm 3.76$ & & $3.99 \pm 0.29$ & & $1.32 \pm 0.08$ & \\
Laser treated & $2.70 \pm 0.02$ & 0.88 & $54.87 \pm 5.54$ & 0.63 & $4.04 \pm 0.06$ & 0.76 & $1.21 \pm 0.17$ & 0.37 \\
Grinded & $2.56 \pm 0.03$ & 0.02 & $53.48 \pm 1.50$ & 0.25 & $4.41 \pm 0.11$ & 0.12 & $1.25 \pm 0.01$ & 0.24 \\
\hline
\end{tabular}

Data represents mean \pm SD of triplicates; $p$ test groups compared to as-printed group 
Fig. 6 In vitro biological test. a Cell proliferation of human primary osteoblasts (OBs); b Cell proliferation of Saos-2 cells; c Matured osteoclasts cells (OCs). ${ }^{*} p<0.05$

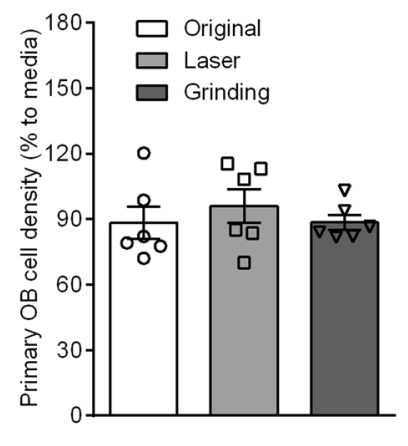

Groups ( $n=6$ per group)

(a)

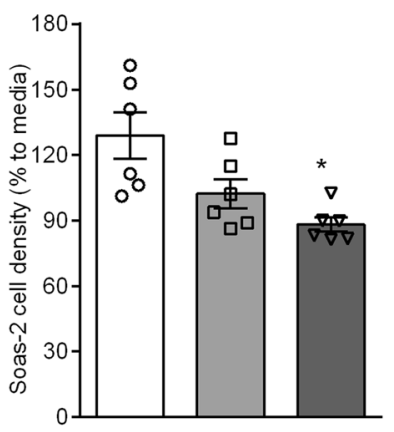

Groups ( $n=6$ per group)

(b)

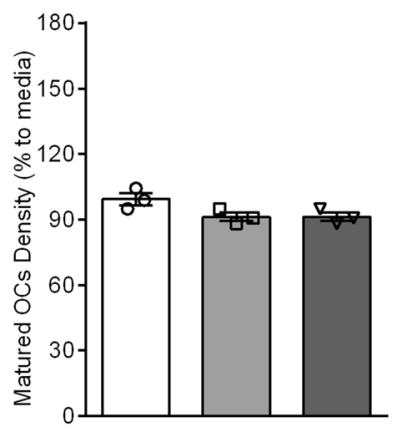

Groups ( $=3$ per group)

(c)
It was reported and experimentally validated that the E-modulus value of ME-made PLA falls within the range of trabecular bone $(0.76-10 \mathrm{GPa})$ and within the lower limit of cortical bone (3.3-20GPa) [49]. The stiffness of PLA was also suitable for maxillofacial applications [14]. For a surgical guidance that requires geometrical accuracy, we recommend to use laser scanning as a post treatment for a better surface quality. However, if tensile functionality is primarily desired, it is more suitable to use an as-printed object without surface treatment, as long as a smooth surface is not highly required. A more accurate conclusion might be gained by expanding the sample size in further study.

\subsection{Laser polishing demonstrated preferable biocompatibility}

We next investigated the influence of laser polishing on the biocompatibility of ME-made PLA samples. After being cultured for 3 days, the cell densities of primary OB cells were analysed and compared among groups. As presented in Fig. 6a, although a slightly higher cell density was observed in laser scanning group than that of as-printed and grinding groups, there was no statistical significance when the laser scanning group was compared to the asprinted and the grinding groups $(p=0.489$ and $p=0.401$, respectively). From Fig. 6b, we observed that the laser scanning group has no statistically significant influence on Saos-2 cell proliferation compared to the as-printed $(p=0.058)$ and grinding $(p=0.084)$ groups. In contrast, analysis based on the cell density revealed a significant decrease in Saos- 2 cells on the surface of grinded samples compared to that of as-printed samples $(p<0.05)$, which might be owing to the surface roughness of grinded samples. These results demonstrate that the samples treated by our designed laser processing parameters are favourable to the growth of bone forming cells. Figure $6 \mathrm{c}$ presents the influence of samples tested on the maturation of human OC cells. The laser scanning group showed no inhibition in the maturation of primary OCs compared to as-printed and grinding groups ( $p=0.074$ and 0.992 , respectively). Those results provide evidences supporting our hypothesis that surface roughness of laser post treated PLA has no toxic effect on either OB or OC cells. The material surface which possesses such a biocompatibility is ideal for use as an intra-operative guidance material in trauma and orthopaedic surgeries.

\section{Conclusion}

We developed a laser surface scanning for the post processing on ME-made PLA samples and demonstrated that the processed PLA samples exhibited good mechanical properties and favourable biocompatibility. Although no conclusive report, by our knowledge to date, has suggested laser method would be applied to the post surface polishing on the ME-made PLA objects, laser post processing can be a useful option to decrease the processing time in fabricating surgical guides for orthopaedic surgery.

We are planning to conduct further study on validating more properties of laser treated ME samples using different characterizing strategies, and comparing the outcome to other post treatment methods.

Acknowledgements Authors are thankful to Mr. Khu Vu in the Research School Physics, and Dr. Zbigniew Stachurski, Chao Hu and Bobin Xing in the Research School of Engineering at the Australian National University for the technical assistance. This work was Australian Orthopaedic Association Research Foundation AOARF2017.

\section{Compliance with ethical standards}

Conflict of interest The authors declare that they have no conflict of interest.

Open Access This article is licensed under a Creative Commons Attribution 4.0 International License, which permits use, sharing, 
adaptation, distribution and reproduction in any medium or format, as long as you give appropriate credit to the original author(s) and the source, provide a link to the Creative Commons licence, and indicate if changes were made. The images or other third party material in this article are included in the article's Creative Commons licence, unless indicated otherwise in a credit line to the material. If material is not included in the article's Creative Commons licence and your intended use is not permitted by statutory regulation or exceeds the permitted use, you will need to obtain permission directly from the copyright holder. To view a copy of this licence, visit http://creativeco mmons.org/licenses/by/4.0/.

\section{References}

1. Gibson I, Rosen DW, Stucker B (2010) Additive maufacturing technologies. Springer, NewYork

2. Petit MA, Beck TJ, Lin HM, Bentley C, Legro RS, Lloyd T (2004) Femoral bone structural geometry adapts to mechanical loading and is influenced by sex steroids: the Penn State Young Women's Health Study. Bone 35(3):750-759

3. Zengin A, Pye SR, Cook MJ, Adams JE, Wu FC, O'Neill TW, Ward KA (2016) Ethnic differences in bone geometry between white, black and south asian men in the UK. Bone 91:180-185

4. Carbone JJ, Tortolani J, Quartararo LG (2003) Fluoroscopically assisted pedicle screw fixation for thoracic and thoracolumbar injuries-technique and short-term complications. Spine 28(1):91-97

5. Austin MS, Vaccaro AR, Brislin B, Nachwalter R, Hilibrand AS, Albert TJ (2002) Image-guided spine surgery-A cadaver study comparing conventional open laminoforaminotomy and two image-guided techniques for pedicle screw placement in posterolateral fusion and nonfusion models. Spine 27(22):2503-2508

6. Farshad M, Betz M, Farshad-Amacker NA, Moser M (2017) Accuracy of patient-specific template-guided vs free-hand fluoroscopically controlled pedicle screw placement in the thoracic and lumbar spine: a randomized cadaveric study. Eur Spine $J$ 26(3):738-749

7. Conlisk N, Howie CR, Pankaj P (2017) Computational modelling of motion at the bone-implant interface after total knee arthroplasty: the role of implant design and surgical fit. Knee 24(5):994-1005

8. Pal N, Quah B, Smith PN, Gladkis LL, Timmers H, Li RW (2011) Nano-osteoimmunology as an important consideration in the design of future implants. Acta Biomater 7(7):2926-2934

9. Radermacher K, Portheine F, Anton M, Zimolong A, Kaspers G, Rau G, Staudte HW (1998) Computer assisted orthopaedic surgery with image based individual templates. Clin Orthop Relat Res 354:28-38

10. Di Giacomo GA, Cury PR, de Araujo NS, Sendyk WR, Sendyk CL (2005) Clinical application of stereolithographic surgical guides for implant placement: preliminary results. J Periodontol 76(4):503-507

11. Wohlers T (2016) Wohlers Report 2016 -3D printing and additive manufacturing state of the industry-annual worldwide progress report. 2016. Wohlers Associates, Inc

12. Rankin TM, Giovinco NA, Cucher DJ, Watts G, Hurwitz B, Armstrong DG (2014) Three-dimensional printing surgical instruments: are we there yet. J surg res 189(2):193-197

13. Petropolis C, Kozan D, Sigurdson L (2015) Accuracy of medical models made by consumer-grade fused deposition modelling printers. Plast Surg 23(2):91-94
14. Wurm MC, Möst T, Bergauer B, Rietzel D, Neukam FW, Cifuentes SC, von Wilmowsky C (2017) In-vitro evaluation of Polylactic acid (PLA) manufactured by fused deposition modeling. J biol eng 11(1):29

15. Juneja M, Thakur N, Kumar D, Gupta A, Bajwa B, Jindal P (2018) Accuracy in dental surgical guide fabrication using different 3-D printing techniques. Addit Manuf 22:243-255

16. Wang Y-T, Yu J-H, Lo L-J, Hsu P-H, Lin C-L (2017) Developing customized dental miniscrew surgical template from thermoplastic polymer material using image superimposition, cad system, and 3d printing. BioMed Res Int. https://doi.org/10.1155/2017/19061 97

17. Ebrahimzadeh A, Azimifar F, Nosouhi R (2016) Design and manufacturing of integrated drilling and cutting orthopedic bonespecific surgical guide. Mater Manuf Process 31(5):608-611

18. Kunz M, Waldman SD, Rudan JF, Bardana DD, Stewart AJ (2012) Computer-assisted mosaic arthroplasty using patient-specific instrument guides. Knee Surg Sport Traumatol Arthrosc 20(5):857-861

19. Cuiffo MA, Snyder J, Elliott AM, Romero N, Kannan S, Halada GP (2017) Impact of the fused deposition ( $\mathrm{fdm}$ ) printing process on polylactic acid (pla) chemistry and structure. Appl Sci 7(6):579

20. Pandey PM, Reddy NV, Dhande SG (2003) Improvement of surface finish by staircase machining in fused deposition modeling. J Mater Process Technol 132(1):323-331

21. Durgun I, Ertan R (2014) Experimental investigation of FDM process for improvement of mechanical properties and production cost. Rapid Prototyp J 20(3):228-235

22. Deligianni DD, Katsala N, Ladas S, Sotiropoulou D, Amedee J, Missirlis YF (2002) Effect of surface roughness of the titanium alloy Ti-6Al-4V on human bone marrow cell response and on protein adsorption. Biomaterials 22(11):1241-1251

23. Sreedhar P, Mathikumar Manikandan C, Jothi G (2012) Experimental investigation of surface roughness for fused deposition modeled part with different angular orientation. Int J Adv Des Manuf Technol 5:21-27

24. Altan M, Eryildiz M, Gumus B, Kahraman Y (2018) Effects of process parameters on the quality of PLA products fabricated by fused deposition modeling (FDM): surface roughness and tensile strength. Mat Test 60(5):471-477

25. Galantucci LM, Lavecchia F, Percoco G (2009) Experimental study aiming to enhance the surface finish of fused deposition modeled parts. CIRP Ann Manuf Technol 58(1):189-192

26. Gajdos I, Slota J (2010) Improving surface finish quality of FDM prototypes. Zeszyty Naukowe Politechniki Rzeszowskiej Mechanika 80(274):87-90

27. Boschetto BA, Bottini $L$ (2015) Surface improvement of fused deposition modeling parts by barrel finishing. Rapid Prototyp J 21(6):686-696

28. Chohan JS, Singh R (2016) Enhancing dimensional accuracy of FDM based biomedical implant replicas by statistically controlled vapor smoothing process. Prog Addit Manuf 1(1-2):105-113

29. Wang D, Wen CY, Chang YN, Lin W, Chen SC (2018) Ultrafast laserenabled 3D metal printing: a solution to fabricate arbitrary submicron metal structures. Precis Eng-J Int Soc Precis Eng Nanotechnol 52:106-111

30. Kurella A, Dahotre NB (2005a) Review paper: surface modification for bioimplants: the role of laser surface engineering. J Biomater Appl 20(1):5-50

31. Rosa B, Mognol P, Hascoët J-y (2015) Laser polishing of additive laser manufacturing surfaces. J Las Appl 27(S2):S29102

32. Gharbi M, Peyre P, Gorny C, Carin M, Morville S, Le Masson P, Carron D, Fabbro R (2013) Influence of various process conditions on surface finishes induced by the direct metal deposition laser technique on a Ti-6Al-4V alloy. J Mater Process Technol 213(5):791-800 
33. Kurella A, Dahotre NB (2005b) Surface modification for bioimplants: the role of laser surface engineering. J Biomater Appl 20(1):5-50

34. Perez Dewey M, Ulutan D (2017) Development of Laser Polishing As an Auxiliary Post-Process to Improve Surface Quality in Fused Deposition Modeling Parts. Proceedings of the ASME 2017 12th International Manufacturing Science and Engineering Conference collocated with the JSME/ASME 2017 6th International Conference on Materials and Processing. Volume 2: Additive Manufacturing; Materials. Los Angeles, California, USA. June 4-8, 2017. Paper No: MSEC2017-3024, V002T01A006; 6 pages, ASME

35. Chai Y, Li RW, Perriman DM, Chen S, Qin QH, Smith PN (2018) Laser polishing of thermoplastics fabricated using fused deposition modelling. Int J Adv Manuf Technol 96(9-12):4295-4302

36. Papon EA, Haque A (2018) Tensile properties, void contents, dispersion and fracture behaviour of 3D printed carbon nanofiber reinforced composites. J Reinf Plast Compos 37(6):381-395

37. Chen L, Zhang X (2019) Modification the surface quality and mechanical properties by laser polishing of AI/PLA part manufactured by fused deposition modeling. Appl Surf Sci 492:765-775

38. E ISO 527-1 (1996) Plastics-Determination of tensile propertiesPart 1: General principles International Organization for Standardization, Geneva, 1996

39. E ISO 604 (2003) Plastics-determination of compressive properties (ISO 604: 2002)

40. Iso S (1997) 178. Plastics, Determination of the bending (in Polish)

41. Wallin RF, Arscott E (1998) A practical guide to ISO 10993-5: Cytotoxicity. Med Device Diagn Ind 20:96-98

42. ISO I S O. 25178-2: 2012-Geometrical Product Specifications (GPS)—Surface Texture: Areal-Part 2: Terms, Definitions and
Surface Texture Parameters[J]. International Standards Organization: Geneva, Switzerland, 2012

43. Ding YF, Li RW, Nakai M, Majumdar T, Zhang DH, Niinomi M, Birbilis N, Smith PN, Chen XB (2016) Osteoanabolic implant materials for orthopedic treatment. Adv Healthc Mater 5(14):1740-1752

44. Anemone G, Weingarten C, Al Taleb A, Prieto C, Farías D (2017) Ultrasmooth metal thin films on curved fused silica by laser polishing. Appl Phys Lett 111(18):181602

45. Yung K, Xiao T, Choy H, Wang W, Cai Z (2018) Laser polishing of additive manufactured $\mathrm{CoCr}$ alloy components with complex surface geometry. J Mater Process Technol 262:53-64

46. Bagsik A, Schöppner V, Klemp E (2010) FDM part quality manufactured with Ultem* 9085 . In: 14th international scientific conference on polymeric materials

47. Sood AK, Ohdar RK, Mahapatra SS (2010) Parametric appraisal of mechanical property of fused deposition modelling processed parts. Mater Des 31(1):287-295

48. Sodeifian G, Ghaseminejad S, Yousefi AA (2019) Preparation of polypropylene/short glass fiber composite as fused deposition modeling (FDM) filament. Results Phys 12:205-222

49. Mow VC, Huiskes R (2005) Basic orthopaedic biomechanics \& mechano-biology, 3rd edn. Lippincott Williams \& Wilkins, Philadelphia, PA

Publisher's Note Springer Nature remains neutral with regard to jurisdictional claims in published maps and institutional affiliations. 